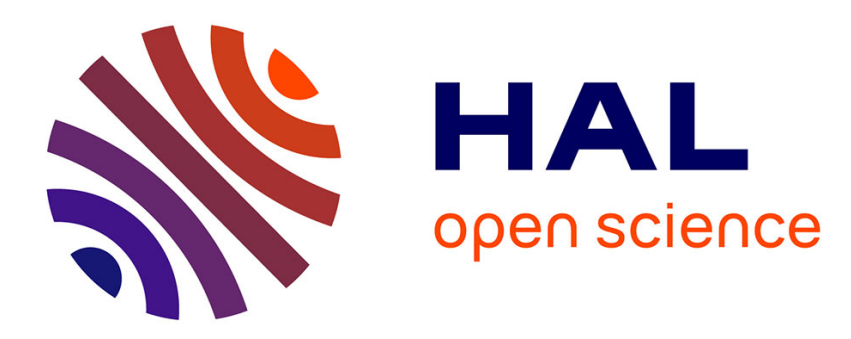

\title{
Influence of terroir products meaning on consumer's expectations and likings
}

François Lenglet

\section{To cite this version:}

François Lenglet. Influence of terroir products meaning on consumer's expectations and likings. Food Quality and Preference, 2014, 32 (C), pp.264-270. hal-01132644

\section{HAL Id: hal-01132644 \\ https://hal.univ-grenoble-alpes.fr/hal-01132644}

Submitted on 9 Feb 2018

HAL is a multi-disciplinary open access archive for the deposit and dissemination of scientific research documents, whether they are published or not. The documents may come from teaching and research institutions in France or abroad, or from public or private research centers.
L'archive ouverte pluridisciplinaire HAL, est destinée au dépôt et à la diffusion de documents scientifiques de niveau recherche, publiés ou non, émanant des établissements d'enseignement et de recherche français ou étrangers, des laboratoires publics ou privés. 


\title{
Influence of terroir products meaning on consumer's expectations and likings
}

\author{
François Lenglet \\ IREGE, University of Savoie, 9 rue de l'arc-en-ciel, BP 240, 74942 Annecy-le-Vieux cedex, France
}

Given the plethora of terroir products, local food companies could find an advantage in specifying their positioning by taking into account vshat the terroir represents for consumers. This research contributes to identifying specific attributes of a terroir in tune with consumer expectations, and tests their capacity to ameliorate consumer hedonic assessments and judgments for these products. Results show the poten-tial of a positioning based on the environment, which is respected by the practices of terroir producers, and which also guarantees the quality of the product.

Keywords:
Terroir
Expectations
Hedonic evaluation
Market-positioning

\section{Introduction}

The market for "terroir" food products has grown remarkably over the past twenty years, notably in France and the rest of Europe, giving rise to numerous research studies (e.g.: Aurier, Fort, \& Sirieix, 2005; Bertozzi, 1995; Bowen \& Zapata, 2009; Elaydi \& Mclaughlin, 2012; Guerrero et al., 2009; Lengard Almli, Verbeke, Vanhonacker, Næs, \& Hersleth, 2011). Marketing is exploiting this growth extensively; in France, for example, there are over 1000 registered trademarks which incorporate the term "terroir" (http://www.inpi.fr). Given this profusion in supply, the evocation of terroir alone soon will lose its capacity to add value to a product. There is thus a critical need to refine positioning strategies through a better understanding of potential differentiation criteria on this market.

After devoting much attention to conceptualising terroir products from the point of view of supply, research efforts now are focusing on demand concerns, in particular to propose consumer-driven definitions (Aurier et al., 2005; Guerrero et al., 2009; Guerrero et al., 2010) and to identify the attributes of a product that contribute most to its overall image (Lengard Almli et al., 2011).

However, these studies consider the terroir product as a global entity, while research findings show that important attributes differ markedly, not only according to consumers (Lengard Almli

\footnotetext{
GIS Alpes-Jura provided financial support for the conduct of this research.

* Tel.: +33 4 50092349; fax: +33450092337.

E-mail address: francois.lenglet@univ-savoie.fr
}

et al., 2011), but also according to the products and terroirs (Aurier \& Fort, 2007). This conforms with the PSO paradigm holding that all human behaviour results from interaction between characteristics of the Person, the Situation, and the Object of the behaviour (Leigh \& Martin, 1981). Likewise, the role of extrinsic attributes of a terroir product should be compared to the role of intrinsic attributes such as the appearance and taste of this product: a recent study re-confirmed the essential role of hedonic motivations in the formation of overall attitudes towards traditional food products, at least for French consumers (Pieniak, Verbeke, Vanhonacker, Guerrero, \& Hersleth, 2009).

This article intends to explore the reasons for the popularity of terroir products, and to study the relative role of the following three types of factors that may explain the perceived value of these products:

- terroir product meanings for the consumer produced by research focussed on consumer-driven definitions;

- extrinsic attributes, which are sources of positioning specific to a terroir product;

- intrinsic attributes that are linked to the taste of a product.

We first describe these factors in detail, then propose a theoretical model of the formation of attitudes regarding a terroir product, and lastly test the model using a traditional cheese typical of Abondance valley, an area located in the Savoie region of the French Alps. The methodology followed and analyses of the results are presented. The discussion examines the theoretical and managerial implications of the results, and we close with proposals for new research avenues. 


\section{The terroir and the consumer}

To pursue the objective of this research, we must first clarify the concept, "terroir", and understand consumer's expectations of terroir products.

\subsection{The concept of terroir}

Today, the term, 'terroir', which has no direct translation in English, is conceptualised in several different disciplines: terroir is referred to by historians, geographers, economists, sociologists, anthropologists, and managers. Furthermore, terroir food products are confused with closely related concepts such as product of origin (region or country) and local products, and definitions diverge depending on whether they are based on the supply point of view (sector actors) or on consumer expectations.

Despite these differences, the majority of actors appear to agree that there are two general dimensions to "terroir": "Terroir is linked to the unique biophysical properties of particular places. . and is also associated with the cultural practices that have maintained these biological resources over several generations...The cultural concept of terroir is understood as the product of interacting natural and human factors" (Bowen \& Zapata, 2009). The specific attributes of a terroir are shaped by natural factors such as the soil, climate, and adaptation of plant varieties to the environment, and by human factors related to history, culture, know-how and tradition.

The definition of a terroir food product also may be elaborated by making a distinction with other closely related concepts. Literature on the effect of country or region of origin generally is evoked when conceptualising a terroir. Starting from the idea of distinguishing country and region of origin (Askegaard \& Ger, 1998), research has refocused on the region of origin and its effect, which is even more powerful when the territory is homogenous and small (Stefani, Romano, \& Cavicchi, 2006), and when there is a high level of congruence between the region and product (Aurier \& Fort, 2005; Van Ittersum, Candel, \& Meulenberg, 2003). This two-dimensionality (natural and human factors) seem to be shared by products of origin and terroir products, but the product-terroir congruence is acquired in the eyes of consumers who perceive the specialisation and typicality of terroirs and their legitimacy to produce the product (Trognon, Lagrange, \& Janin, 1999).

Definitions of terroir products finally are very close to those of traditional food products, which implicitly suggest the same bi-dimensional structure: "a product frequently consumed or associated with specific celebrations and/or seasons, normally transmitted from one generation to another, made accurately in a specific way according to the gastronomic heritage, with little or no processing/manipulation, distinguished and known because of its sensory properties and associated with a certain local area, region or country" (Guerrero et al., 2009).

The attributes related to natural and human factors form images of a terroir such as proposed in consumer-driven definitions, and consequently should influence the perceived value of a product.

\subsection{Modelling terroir food product consumption behaviour}

The attributes of a terroir food product are perceived through two types of stimuli:

- When buying or first encountering the product, the consumer is subjected to "informational" stimuli (e.g. price, brand, ingredients, label, nutritional and environmental claims, etc.; Steenkamp, 1989), which shape expectations. These also result from the consumer's a priori image of the terroir product.

- The actual consumption of a product then confronts the consumer with sensory stimuli perceived by the five senses, e.g. appearance, colour, size, shape, texture, odour, aroma, taste, temperature, which leads the consumer to form an assessment of the product.

The consumer's overall judgement finally will lean towards either the expectations or the assessment produced by tasting alone, depending on the influence of respective types of stimuli and the resulting phenomena of assimilation or contrast (see, for example, Schifferstein, Kole, \& Mojet, 1999, for a review). Individual or contextual factors outside the product also can influence expectations, the gustatory evaluation, and the overall judgement, and also moderate relations between expectations and assessments on one hand, and the overall judgement on the other. This classic stimuli-response approach in sensory marketing is diagrammed in Fig. 1.

This base model enables one to assess the role of the perceived sources of a terroir product. For economic actors in the terroir sector, informational stimuli represent a marketing action variable: it is possible to focus communication on the human factor, the natural factor, the origin, know-how, history, etc. attributes, depending on the positive impact obtained with regard to expectations and overall judgement. A relevant criteria of differentiation is identified when the stimulus carrying it leads to higher expectations (compared to another criteria), and when overall judgment is better compared to when assessment is based on tasting alone (positive deviation due to information). In contrast, consumer images of terroir impose on marketing strategies, as do sensorial stimuli, at least when these mainly result from a fixed process (label or specifications, for example).

The model then can be validated empirically by testing the role of potential differentiation criteria for a terroir food product, presented in the form of informational stimuli, on consumer expectations and judgement.

\section{Materials and methods}

An empirical study allowed the proposed model to be applied to Abondance cheese, a food that is emblematic of a Savoie terroir and which benefits from a protected designation of origin label (AOC: Appelation d'Origine Contrôlée). The informational stimuli tested were scenarios illustrating certain characteristics of the terroir corresponding to two factors (natural and human) identified in the literature. The experimental protocol followed rendered it possible to measure consumer images of terroir for Abondance cheese, submit these images to stimuli, and evaluate the resulting expectations, assessments, and overall judgements.

\subsection{Material stimuli}

\subsubsection{Cheeses}

The terroir product used in this study is a hard pressed cheese that is allowed to mature for at least 100 days on spruce boards. The organoleptic characteristics of this cheese are fairly consistent

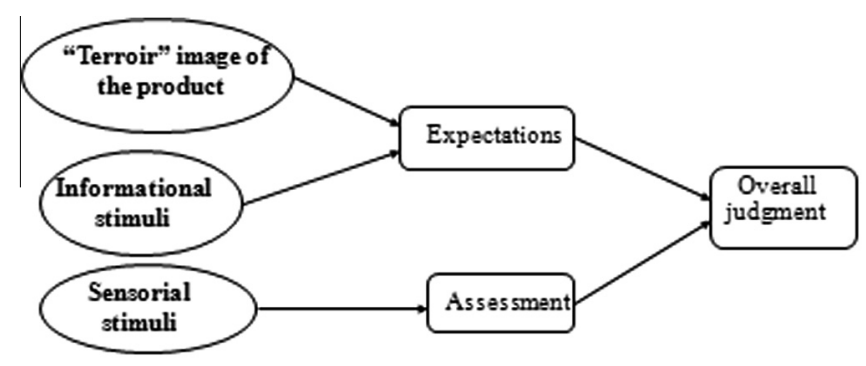

Fig. 1. Base model for the evaluation of a terroir food product. 
from one producer to another. Two types of Abondance cheese are sold, farm and dairy; the type is determined by whether the milk used to make the cheese comes from a single farm or several farms. For the study, four cheeses of each type were selected by interprofessional organisations in the Abondance sector. One cheese served as a training product. The cheese selected has the typical sensorial profile of Abondance cheese. In conformance with current practices in experimental economics, the three other cheeses selected actually correspond to the terroir characteristics and were produced by the producers described in the informational stimuli.

\subsubsection{Informational stimuli}

The potential differentiation criteria for Abondance cheese were defined on the basis of a literature review and two focus groups involving 19 adult subjects, buyers and consumers of local cheeses: the goal was to elicit the dimensions and attributes of terroir products, in particular mountain cheese. The differentiation criteria used were formulated in the form of scenarios by a committee composed of cheese sector professionals and researchers specialised in marketing. Two attributes were selected for each factor (human and natural): the human factor was illustrated by the artisanal character, and more precisely the small size of the production unit, as well as a cooperative social organisation; the natural factor was represented by environmental preservation thanks to extensive production practices, and the quality of the environment as a guarantee of the quality of the cheese. Two scenarios corresponding to natural and human factors were the same for the dairy and farm cheese types: "environmental preservation" and "small production/small producer". Due to its inherent nature, the "cooperative" scenario was specific to dairy cheeses, and the "environment serving quality" was attributed to farm cheeses.

In order to test the possible superiority of these attributes in relation to other characteristics of supply that are less directly linked to the terroir, other scenarios also were formulated. These involved other potential product selection criteria, such as the reputation of the distributor (well known cheese-maker) or producer (locally known cheese-making business) or the presence of an unofficial mark or sign of quality (first prize in an agricultural contest, store brand with an image of terroir). The wording of each scenario is presented in Table 1. For dairy and farm cheeses, scenarios 1,3 , and 5 illustrated specific terroir attributes, and actually correspond to the cheeses used in the blind tests. All five scenarios were presented to collect expectations. Scenarios 1, 3, and 5 also were used to obtain the overall judgments (tasting with information).

The measurement of expectations resulting from scenarios took the form of a 10 point differential semantic scale ranging from "I probably will not like at all" to "I probably will like very much" in response to the question: "For each of these Haute-Savoie AOC Abondance cheeses, and in the light of the information provided, please state how you expect you will like them".

\subsection{The experimental protocol}

The protocol, carried out in a sensory assessment laboratory, incorporated three types of stimuli (sensory alone, information alone, combined) and began with blind tastings. The next step consisted of assessing the expectations induced by the information. The protocol concluded with the evaluation of the combined stimuli that allows a subject to associate the taste with the product. It avoided the contiguity of two evaluation measurements by interjecting a three-week period between sessions: the subjects participated in a first laboratory phase during which they evaluated blind the products proposed, and declared their expectations. They then returned for a second phase, which allowed their hedonic assessments to be collected with information on the criteria. The cheeses tested were exactly the same for both phases (blind tasting and informed tasting). During the interim period between the two phases, the cheeses were refrigerated to impede the continuation of the ripening process.

During the two phases, the same respondent only tasted the farm Abondance or the dairy Abondance cheese. The sample was constituted by the partner sensory evaluation laboratory. It included 325 Savoie inhabitants, cheese consumers who had consumed Abondance cheese at least once over the preceding 6 months. The average age was 45.6 years and the gender breakdown was balanced (45\% men, 55\% women). In this study, the total sample was divided into two groups of equal size (dairy cheeses, $n=160$; farm cheeses, $n=165$ ).

Concretely, the subjects participating in the experiment underwent the following protocol.

\section{First test phase (session 1)}

The protocol for the two types of products (farm and dairy) was exactly the same in terms of the order of operations.

- Blind testing and hedonic evaluation of four portions of Abondance cheese, in sequential monadic order: tasting a training product, then three products corresponding to three terroir attributes (marked ${ }^{\mathrm{a}}$ or $^{\mathrm{b}}$ in Table 1 ; scenarios not communicated); the hedonic evaluations were measured with a 10 point semantic differential scale ranging from "I do not like at all" to "I like very much".

- Presentation of a self-administered questionnaire to collect individual characteristics.

- Presentation of a self-administered questionnaire to collect expectations in response to the five scenarios illustrating three terroir and two non terroir attributes (Table 1) regarding Abondance cheeses.

\section{Second test phase (session 2, three weeks later)}

- Informed testing and hedonic evaluation of four portions of Abondance cheese, in sequential monadic order: tasting a training product, then three products associated with three scenarios illustrating terroir attributes (marked ${ }^{a}$ or $^{b}$ in Table 1; scenarios communicated this time). A scenario also was communicated for the training product: "this is an Abondance dairy/farm cheese made in the Haute-Savoie. It has a French AOC label". The measurement of the hedonic evaluation was exactly the same as that used in Phase 1.

- Presentation of a self-administered questionnaire to collect individual perceptions of the terroir image of an Abondance cheese. The measurement of terroir images corresponding to natural and human factors was adapted to the scale proposed by Aurier et al. (2005): a set of 9 items (territory, region, land, mountain, history, ritual, know-how, recipe, tradition), with five-point Likert scales and introduced by the question: "From your own point of view, what determines Abondance as a terroir product is...".

\subsection{Statistical treatment}

\subsubsection{Capacity of specific terroir criteria to better valorise a consumer's expectations in relation to other criteria}

$T$-tests comparing means for paired samples were performed on the five expectation scores (based on the scenarios) to determine whether the three scenarios illustrating characteristics specific to the terroir were better appreciated than other, more generic scenarios. 
Table 1

Information stimuli presented in scenario form.

\begin{tabular}{|c|c|}
\hline Cheeses \& Criteria & Scenarios (Abondance Dairy) \\
\hline 1. Small producer ${ }^{\mathrm{a}}$ & $\begin{array}{l}\text { This AOC Abondance cheese is made at a small cheese making facility in Chapelle d'Abondance by Joël Bouvier, an artisanal } \\
\text { cheese maker. He transforms the milk of } 9 \text { farmers located around the commune }\end{array}$ \\
\hline 2. Reputation & $\begin{array}{l}\text { This AOC Abondance cheese is made in the workshops of the Pochat \& Fils cheese making facility located near Evian on the } \\
\text { heights above Lake Leman. It ripens for a period of } 5 \text { months }\end{array}$ \\
\hline 3. Cooperative ${ }^{a}$ & $\begin{array}{l}\text { This AOC Abondance cheese is produced by the Gruffy Cooperative: a cooperative of } 20 \text { producers who have pooled their } \\
\text { financial resources to make and sell their products. In this way, they share in an equitable manner the fruit of their work }\end{array}$ \\
\hline 4. Store brand & $\begin{array}{l}\text { This AOC Abondance cheese is sold under the label "Our regions have talent" (Leclerc stores). It has a fat content of } 33 \% \text { and } \\
\text { it ripens for at least } 3 \text { months }\end{array}$ \\
\hline $\begin{array}{l}\text { 5. Environment }{ }^{\mathrm{b}} \text { preserved through } \\
\text { agricultural pratices }\end{array}$ & $\begin{array}{l}\text { This AOC Abondance cheese, made at Féternes cheese making facility, is produced through mountain farming, which, } \\
\text { through its environmentally friendly practices (extensive grazing, limited fertilizer), preserves water quality in the Evian } \\
\text { basin }\end{array}$ \\
\hline \multicolumn{2}{|l|}{ Scenarios (Abondance Farm) } \\
\hline 1. Small producer ${ }^{a}$ & $\begin{array}{l}\text { This AOC Abondance cheese is made by Sylvie and Dominique Grillet-Aubert, small producers established in Saint-Paul en } \\
\text { Chablais. Every day, they transform the milk of their } 20 \text { cow herd into cheese }\end{array}$ \\
\hline 2. Expert cheese maker & $\begin{array}{l}\text { This AOC Abondance cheese is selected, ripened, and marketed by Pierre Gay, an expert cheese-maker established in Annecy. } \\
\text { The cheese ripens in the centuries-old caves of one of the most beautiful cheese-making facilities in France }\end{array}$ \\
\hline 3. Environment ${ }^{\mathrm{b}}$ serving quality & $\begin{array}{l}\text { This AOC Abondance cheese is made by the Gallay farm, in Chévenoz, in Abondance valley. The dairy cows graze on prairies } \\
\text { rich with mountain flowers. The altitude, absence of pollution and biodiversity make this Abondance cheese a very healthy } \\
\text { product }\end{array}$ \\
\hline 4. Awards & $\begin{array}{l}\text { This AOC Abondance farm cheese, produced by GAEC le Géant in Châtel, won the first prize at the annual } 2009 \text { Abondance } \\
\text { cheese contest organised in October during the Abondance farm fair }\end{array}$ \\
\hline $\begin{array}{l}\text { 5. Environment }{ }^{\mathrm{b}} \text { preserved through } \\
\text { agricultural pratices }\end{array}$ & $\begin{array}{l}\text { This AOC Abondance farm cheese is produced by the GAEC le Mont Chauffé in Abondance on a mountain farm that, through } \\
\text { its environmentally friendly practices (extensive grazing, limited fertilizer), contributes to the conservation of protected } \\
\text { areas (Natura } 2000 \text { zone) }\end{array}$ \\
\hline
\end{tabular}

a Terroir attributes related to the human factor.
b Terroir attributes related to the natural factor.

\subsubsection{Capacity of specific terroir criteria to improve the overall} judgement of a product in relation to blind tasting (hedonic deviation due to positive information)

To evaluate the relative influence of information specific to terroir and taste, the first step was to calculate differential scores. They compared the expectations and blind evaluations (disconfirmation), expectations and overall judgement (shift in response due to taste), the overall judgement and blind evaluations (shift in response due to information). One sample $T$-test then was carried out on the differential scores to check their significance.

\subsubsection{Impact of terroir images on expectations and overall judgement} with regard to a product

To represent the terroir images of the products, a Principal Component Analysis (PCA) was performed on the items of the scale proposed by Aurier et al. (2005). Factor loadings were saved as new variables, and correlations and regressions were used to test the relationship between the terroir image of the product, expectations and overall judgment.

\section{Results}

\subsection{Impact of criteria on expectations}

For dairy cheeses, all of the expectations based on attributes of the terroir are significantly superior to other expectations (Fig. 2). The highest expectations regard scenario 5 (environmental preservation through agricultural practices) and scenario 1 (small production), followed by scenario 3 (cooperative) also based on the terroir. Scenario 2 (reputation) and scenario 4 (store brand with a terroir positioning) showed the weakest expectations. It thus appears that exposing consumers to precise information regarding the natural and human dimensions of a terroir (scenarios 1, 3, 5) significantly improve their expectations in comparison to more neutral information about the product $(p \leqslant 0.007)$.

In the case of farm cheeses, only expectation 3 (environment serving quality) differed significantly from the others $(p \leqslant 0.02)$. The other expectations were comparable at $p=0.05$ (Fig. 3 ). Here again, it is a specific feature of the terroir that best valorises the product. Nonetheless, neither of the two other terroir attributes tested, whether they corresponded to the natural factor (environmental preservation thanks to extensive agricultural practices) or the human factor (small producer), proved to be superior compared to other more conventional attributes (reputation, awards).

In the end, four out of six terroir criteria permitted a priori expectations regarding the product to be better valorised. There was no evidence that non-specific terroir informational stimuli are more effective for either dairy or farm cheeses. This result suggests the potential utility in communicating certain specific terroir attributes rather than more generic, extrinsic product attributes (reputation of the producer or distributor, overall image of the terroir, quality sign). It was observed that beyond the category (dairy or farm cheese), the two most valued attributes were related to the natural factor.

\subsection{Impact of the criteria on the hedonic deviations}

With the exception of farm cheese F5 (scenario: environmental preservation thanks to agricultural practices), all of the cases correspond to a negative disconfirmation of expectations: (E-B) is significantly different from zero and the cheeses are not as good as expected (Table 2). Furthermore, the hedonic deviation due to sensory processes, in other words, the difference between the informed hedonic evaluation (or overall judgement) and expectations ( $\mathrm{I}-\mathrm{E})$ is negative and significant $(p<0.001)$. Information about the terroir is not enough to maintain expectation levels at the moment of overall judgement.

However, it is interesting to observe the cases where the hedonic deviation due to information, meaning the difference between the informed hedonic evaluation and the blind hedonic evaluation (I-B), is significant: this situation reflects the capacity of a scenario to influence consumer opinion and to improve the overall judgement in relation to the initial assessment. This was observed for the following scenarios:

- D3: "cooperative" in dairy cheese $(p=0.016)$. 


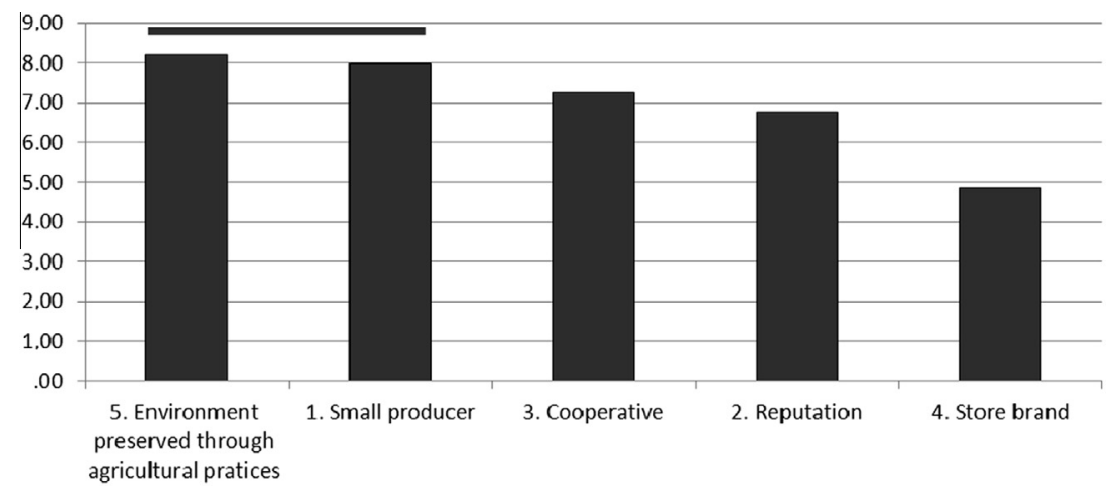

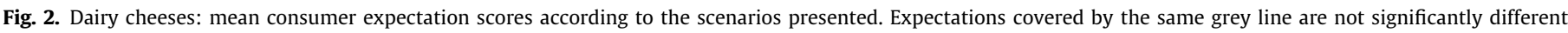
according to the $T$-test.

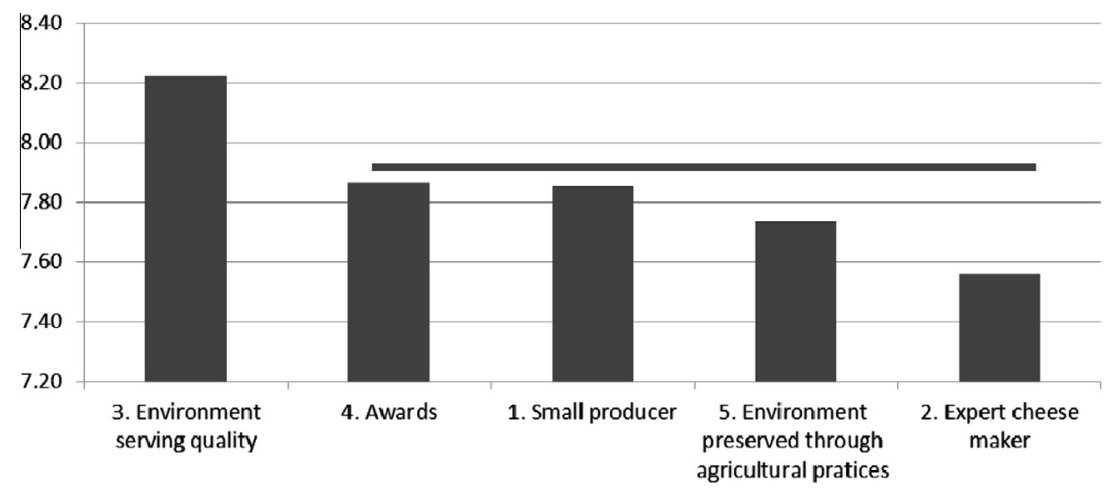

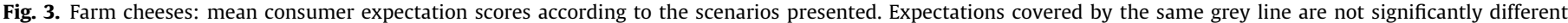
according to the $T$-test.

Table 2

Shifts in judgements between blind tasting, expectations, and informed tasting.

\begin{tabular}{|c|c|c|c|c|c|c|}
\hline \multirow[t]{3}{*}{ Cheeses } & \multicolumn{4}{|c|}{ Shift in response due to: } & \multirow{2}{*}{\multicolumn{2}{|c|}{ Disconfirmation }} \\
\hline & \multicolumn{2}{|c|}{ Information } & \multicolumn{2}{|l|}{ Taste } & & \\
\hline & $\mathrm{I}-\mathrm{B}^{\mathrm{a}}$ & $p$ & $I-E^{b}$ & $p$ & $\mathrm{E}-\mathrm{B}^{\mathrm{c}}$ & $p$ \\
\hline D1: Small producer & .38 & .074 & -.87 & .000 & 1.23 & .000 \\
\hline D3: Cooperative & .53 & .016 & -1.38 & .000 & 1.86 & .000 \\
\hline D5: Environmental preservation & .74 & .000 & -2.46 & .000 & 3.20 & .000 \\
\hline F1: Small producer & .21 & .401 & -2.72 & .000 & 2.91 & .000 \\
\hline F3: Environment serving quality & .89 & .000 & -2.17 & .000 & 3.02 & .000 \\
\hline F5: Environmental preservation & .20 & .237 & .09 & .622 & .15 & .507 \\
\hline
\end{tabular}

Values in bold are significantly different from zero $(p<0.05)$.

$D_{i}=$ dairy cheeses; $F_{i}=$ farm cheeses, with $i=$ number of the scenario.

a $\mathrm{I}-\mathrm{B}=$ Informed tasting scores minus blind tasting scores.

b $\mathrm{I}-\mathrm{E}=$ Informed tasting scores minus expected scores.

c $\mathrm{E}-\mathrm{B}=$ Expected scores minus blind tasting scores.

- D5: "environmental preservation thanks to agricultural practices" in dairy cheese $(p<0.001)$.

- F3: "environment serving product quality" in farm cheese $(p<0.001)$.

Furthermore, two of these scenarios, specific to the natural dimension of the terroir, also corresponded to the highest expectations (Figs. 2 and 3). Finally, three of the four attributes that generated higher expectation levels allowed a significant improvement in the consumer's overall judgement after tasting. Note further than in the case of D1 (small producer), the hedonic deviation due to information is close to the level of significance.

For these four scenarios (including D1), an assimilation effect exists, since $(\mathrm{I}-\mathrm{B}) /(\mathrm{E}-\mathrm{B})>0$. But this effect is not complete because the differences (I-E) are significantly different from zero: when consumers are informed of the characteristics of the terroir, the taste evaluation remains important in the overall judgement. This result is consistent with previous research (e.g.: Siret \& Issanchou, 2000).

\subsection{Impact of product "terroir" images on expectations and overall judgement}

Concerning the data sample on dairy cheeses, it was possible to conduct a factor analysis on the terroir image scale (KMO index $=0.798$ ). The scree-test revealed a single dimension. The eigenvalue of the first component was 3.635 and accounted for $40.39 \%$ of the variance. The scale had a good reliability (Cronbach's alpha $=0.812$ ). 
Table 3

Correlations between Terroir image and product assessments (dairy cheeses).

\begin{tabular}{|c|c|c|c|c|c|c|}
\hline \multirow[b]{2}{*}{ Pearson correlation } & \multicolumn{2}{|c|}{ Expectations } & \multirow[b]{2}{*}{$\begin{array}{l}\text { D5: Environmental } \\
\text { preservation }\end{array}$} & \multicolumn{3}{|c|}{ Overall judgment (informed tasting) } \\
\hline & $\begin{array}{l}\text { D1: Small } \\
\text { production }\end{array}$ & $\begin{array}{l}\text { D3: } \\
\text { Cooperative }\end{array}$ & & $\begin{array}{l}\text { D1: Small } \\
\text { production }\end{array}$ & $\begin{array}{l}\text { D3: } \\
\text { Cooperative }\end{array}$ & $\begin{array}{l}\text { D5: Environmental } \\
\text { preservation }\end{array}$ \\
\hline $\begin{array}{c}\text { Terroir Image of } \\
\text { Abondance }\end{array}$ & $.212^{* *}$ & $.195^{* *}$ & $.222^{*}$ & $.117^{\mathrm{ns}}$ & $.161^{*}$ & $.131^{\mathrm{ns}}$ \\
\hline
\end{tabular}

Correlations in bold are significant $(p<0.05)$.

ns $=$ not significant

${ }^{*} p<0.05$.

${ }^{* *} p<0.01$.

Table 4

The measurement of Abondance farm cheese terroir image (factor analysis).

\begin{tabular}{lll}
\hline & Component & \\
\cline { 2 - 3 } & F1: Natural factor & F2: Human factor \\
\hline Region & 0.896 & \\
Territory & 0.832 & \\
Land & 0.561 & \\
Mountain & 0.559 & 0.369 \\
History & 0.503 & 0.780 \\
Recipe & & 0.699 \\
Ritual & & 0.692 \\
Know-how & & 0.647 \\
Tradition & & 0.723 \\
Cronbach's $\alpha$ & 0.760 & \\
\hline
\end{tabular}

Table 5

Impact of Terroir image on product assessments (farm cheeses).

\begin{tabular}{|c|c|c|c|c|}
\hline \multirow[b]{2}{*}{$\begin{array}{l}\text { Dependant } \\
\text { variables }\end{array}$} & \multirow[b]{2}{*}{ Farm cheeses } & \multicolumn{2}{|c|}{ Standardised beta } & \multirow[t]{2}{*}{$R^{2}$} \\
\hline & & $\begin{array}{l}\text { F1 Natural } \\
\text { factor }\end{array}$ & $\begin{array}{l}\text { F2 Human } \\
\text { factor }\end{array}$ & \\
\hline \multirow[t]{3}{*}{ Expected scores } & F1 Small producer & $0.051^{\mathrm{ns}}$ & $0.138^{\mathrm{ns}}$ & 0.028 \\
\hline & $\begin{array}{l}\text { F3 Environment } \\
\text { serving quality }\end{array}$ & 0.170* & 0.185* & 0.090 \\
\hline & $\begin{array}{l}\text { F5 Environmental } \\
\text { preservation }\end{array}$ & $0.156^{\mathrm{a}}$ & 0.199* & 0.091 \\
\hline \multirow{3}{*}{$\begin{array}{c}\text { Informed } \\
\text { tasting } \\
\text { scores }\end{array}$} & F1 Small producer & $-0.085^{\mathrm{ns}}$ & $0.153^{\mathrm{ns}}$ & 0.020 \\
\hline & $\begin{array}{l}\text { F3 Environment } \\
\text { serving quality }\end{array}$ & $0.278^{*}$ & $-0.078^{\mathrm{ns}}$ & 0.065 \\
\hline & $\begin{array}{l}\text { F5 Environmental } \\
\text { preservation }\end{array}$ & $-0.014^{\mathrm{ns}}$ & $0.212^{*}$ & 0.043 \\
\hline
\end{tabular}

Standardised beta and $R^{2}$ in bold are significant $(p<0.05)$.

ns $=$ not significant.

${ }^{*} p<0.05$.

a $p=0.067$.

It was possible to verify the existence of links between the perceived image of terroir for Abondance cheese and consumer's expectations or overall judgement when submitted to information about the terroir (Table 3). For dairy Abondance cheeses, expectations were linked in a systematic manner to the image of terroir. The more powerful terroir brand equity was, the higher were consumer's expectations. Results were more nuanced for overall judgements. Additionally, one should note that correlations were not significant when expectations were based on scenarios that only mentioned terroir in a general manner without evoking either natural or human attributes (terroir store brand: $p=0.074$; reputation of cheese-maker: $p=0.273$ ). This result confirms the added value of a positioning strategy based on specific attributes rather than merely mentioning the terroir.

Concerning farm cheeses, factor analysis had a KMO index of 0.766. Using a Promax type of oblique rotation like the one used by the authors of the scale (Aurier et al., 2005) the analysis revealed a bi-dimensional structure of the terroir construct: one factor corresponded to the natural dimension of a terroir while the second factor regrouped elements related to human dimensions (Table 4). Cronbach's alphas showed a good scale-reliability.

The relatively low correlation factors $(r=0.426)$ allowed multiple regressions to be performed to explain the expectations and overall judgments by the image of the terroir (Table 5).

For farm cheese evaluations based on a specific human attribute (small producer), terroir brand equity had no influence. In contrast, farm cheese expectations based on a natural attribute (environment) were linked in a quasi-systematic manner to the two dimensions of the image of terroir.

The contribution of the two dimensions of the image of the terroir seem to be comparable. The results of Aurier et al. (2005) showed an effect of only the natural factor on attitudes towards terroir products. However, this attitude was not measured after exposure to informational and/or sensory stimuli, but simply declared $a$ priori on a like/dislike scale. The results are more nuanced for overall judgements. Additionally, one should note that regressions are not significant for expectations based on scenarios which simply evoke a terroir (expert cheese-maker, and awards). For farm cheeses, the perceived image of terroir positively influence expectations based on the highlighting of natural attributes of the product.

\section{Discussion}

This study empirically confirms the idea that the explicit statement of a terroir attribute may influence the assessment of a food product more efficiently than simply mentioning the region of origin (Van Ittersum et al., 2003). The observation of differentiated effects for natural and human factors also raises a number of questions. While this result is consistent with previous studies about the effect of country or region of origin (Van Ittersum et al., 2003; Verlegh, 2001), the attributes of the natural factor have a particular influence on attitudes towards food products while the attributes of the human factor are more important with regard to industrial products. Nevertheless, even for very similar foods, the specificity (dairy or farm cheese) seems to play an important role: for dairy cheeses, the human factor (scenarios D1 and/or D3) influences the level of expectations, the hedonic deviation, and the impact of the image of terroir on the expectations or the overall judgment. However, for farmer cheeses, no effect of the human factor was observed. One possible explanation is that consumers probably consider farm production as artisanal and small (nonindustrial). Thus, the "Small Producer" scenario (F1) does not provide additional information and therefore does not change the perception of the product.

The specific characteristics of a terroir food product may only be relevant differentiation criteria if they respond positively to consumer's motivations: for example, the characteristics related to the human factor can satisfy ideological motivations (e.g.: support the local economy, Lengard Almli et al., 2011) and those related to the natural factor can reflect a need for reassurance in relation 
to health concerns (e.g.: a correlation of 0.74 between health and naturalness motivations, Pieniak et al., 2009). However, the ethical and environmental behaviours stem from various motivations and these behaviours may be motivated by self-interest rather than altruism: a study shows that consumer motivations for purchasing organic dairy products were first taste, food safety and health benefits, far ahead of environmental and ethical motivations (McEachern \& McClean, 2002). Thus, for terroir food products, environmental concerns may correspond more to health concerns than ecological concerns. This probably depends on the level of consumer's regional ethnocentrism. Moreover, consumers with a greater sense of regional ethnocentrism could be more sensitive to terroir characteristics related to the human factor because they feel proud when they purchase regional products and support regional businesses (Fernández-Ferrín \& Bande-Vilela, 2013).

\section{Conclusion}

The main goal of this study was to verify if certain specific characteristics of a terroir could valorise a product originating from it, and therefore explicitly contribute to the positioning of the product. The results show that in the case of Abondance cheese, communicating the natural dimension of a terroir (attributes evoking the environment) achieves the most positive impact on productrelated expectations for both dairy and farm type cheeses. For the dairy type, expectations formed based on information regarding the human dimension of terroir (small producer and cooperative) take second and third position.

In addition, it appears that attributes evoking the environment significantly improve overall judgement compared to blind tasting alone. Taking the environment into account thus seems to be interesting to promote both a purchase (impact on expectations) and a re-purchase (improvement of the overall judgement after consumption). Information on human organisation (cooperative) has comparable effects for the dairy type Abondance cheese. Finally, the way by which the consumer perceives the terroir influences significantly his or her expectations, if, to a lesser extent, his or her overall judgment of the product. The more powerful the terroir brand equity is, the more the terroir attributes of a product are valued by the consumer. This is all the more significant when these attributes concern the environment, and this is in agreement with the suggestion of Pieniak et al. (2009) for whom, "the natural character or image of traditional foods constitutes one of its major assets vis-à-vis consumers".

These results suggest new opportunities for marketing terroir products:

- Advertising and packaging should emphasise a terroir's specific attributes, especially those corresponding to its natural dimension, rather than a general terroir image;

- The effectiveness of such a position is strengthened when the terroir benefits from a powerful image: companies that manufacture terroir products should highlight not only the product, but also the terroir, in partnership with institutional stakeholders.

This research has some limitations linked to the validity of the scale of terroir images and to the stability of its dimensions. These points therefore should be investigated further. Likewise, future studies using other differentiation criteria and other terroir products should be envisioned.

Moving beyond the results and their implications, it would be useful to pursue research on how a terroir is conceived and perceived and the consequences from the consumer's point of view. New research appears necessary to better understand the links between food motivations, the terroir image of the product, and reactions to terroir-specific stimuli.

With a view of positioning and segmentation, the study of interactions between products, terroirs, and consumers should prove to be fruitful. In particular, the need to differentiate the marketing of terroir products according to the target (terroir residents versus non-residents, or tourists) merits new studies.

\section{References}

Askegaard, S., \& Ger, G. (1998). Product-country images: Towards a contextualized approach. European Association for Consumer Research, 3, 50-58.

Aurier, P., Fort, F., \& Sirieix, L. (2005). Exploring terroir product meaning for the consumer. Anthropology of Food, 4, 16.

Aurier, P., \& Fort, F. (2007). The effects of perceived congruity between origin, brand and product on the purchase intention of a branded product of origin. Advances in Consumer Research, 34, 55-63.

Bertozzi, L. (1995). Designation of origin: Quality and specification. Food Quality and Preference, 6, 143-147.

Bowen, S., \& Zapata, A. V. (2009). Geographical indication, terroir, and socioeconomic and ecological sustainability: The case of tequila. Journal of Rural Studies, 25, 108-119.

Elaydi, R., \& McLaughlin, J. (2012). Cultivating terroir in subsistence markets Development of terroir strategy through harmony-with-community framework. Journal of Business Research, 65(12), 1743-1748.

Fernández-Ferrín, P., \& Bande-Vilela, B. (2013). Regional ethnocentrism: Antecedents, consequences, and moderating effects. Food Ouality and Preference, 30(2), 299-308.

Guerrero, L., Claret, A., Verbeke, W., Enderli, G., Zakowska-Biemans, S., Vanhonacker F., et al. (2010). Perception of traditional food products in six European regions using free word association. Food Quality and Preference, 21(2), 225-233.

Guerrero, L., Guàrdia, M. D., Xicola, J., Verbeke, W., Vanhonacker, F., ZakowskaBiemans, S., et al. (2009). Consumer-driven definition of traditional food products and innovation in traditional foods. A qualitative cross-cultural study. Appetite, 52(2), 345-354.

Leigh, J. H., \& Martin, C. R. (1981). A review of situational influence paradigms and research. In B. M. Enis \& K. J. Roering (Eds.), Review of marketing (pp. 57-74). Chicago: American Marketing Association.

Lengard Almli, V., Verbeke, W., Vanhonacker, F., Næs, T., \& Hersleth, M. (2011). General image and attribute perceptions of traditional food in six European countries. Food Quality and Preference, 22(1), 129-138.

McEachern, M. G., \& McClean, P. (2002). Organic purchasing motivations and attitudes: Are they ethical? International Journal of Consumer Studies, 26, 85-92.

Pieniak, Z., Verbeke, W., Vanhonacker, F., Guerrero, L., \& Hersleth, M. (2009). Association between traditional food consumption and motives for food choice in six European countries. Appetite, 53, 101-108.

Schifferstein, H. N. J., Kole, A. P. W., \& Mojet, J. (1999). Asymmetry in the disconfirmation of expectations for natural yogurt. Appetite, 32(3), 307-329.

Siret, F., \& Issanchou, S. (2000). Traditional process: Influence on sensory properties and on consumer's expectation and liking application to 'pâté de campagne'. Food Quality and Preference, 11, 217-228.

Steenkamp, J.-B. E. M. (1989). Product quality. Herndon (VA): Books International.

Stefani, G., Romano, D., \& Cavicchi, A. (2006). Consumer expectations, liking and willingness to pay for specialty foods: Do sensory characteristics tell the whole story? Food Quality and Preference, 17, 53-62.

Trognon, L., Lagrange, L., \& Janin, S. (1999). Attitudes des consommateurs vis-à-vis des produits alimentaires régionaux - Le cas de l'Auvergne. Industries Alimentaires et Agricoles, 4, 107-112.

Van Ittersum, K., Candel, M. J. J. M., \& Meulenberg, M. T. G. (2003). The influence of the image of a product's region of origin on product evaluation. Journal of Business Research, 56(3), 215-226.

Verlegh, P.W.J. (2001). Country-of-origin effects on consumer product evaluations, Unpublished Phd Dissertation, Wageningen University, Wageningen, the Netherlands. 